Article

\title{
Controllable Hydrothermal Conversion from Ni-Co-Mn Carbonate Nanoparticles to Microspheres
}

\author{
Yanqing Tang, Yangcheng $\mathrm{Lu}^{*}$ and Guangsheng Luo \\ State Key Laboratory of Chemical Engineering, Department of Chemical Engineering, Tsinghua University, \\ Beijing 100084, China; tyq15@mails.tsinghua.edu.cn (Y.T.); gsluo@tsinghua.edu.cn (G.L.) \\ * Correspondence: luyc@tsinghua.edu.cn; Tel./Fax: +86-10-6277-3017
}

Academic Editor: Monica Distaso

Received: 2 October 2016; Accepted: 18 November 2016; Published: 23 November 2016

\begin{abstract}
Starting from Ni-Co-Mn carbonate nanoparticles prepared by microreaction technology, uniform spherical particles of $\mathrm{Ni}_{1 / 3} \mathrm{Co}_{1 / 3} \mathrm{Mn}_{1 / 3} \mathrm{CO}_{3}$ with a size of 3-4 $\mu \mathrm{m}$ were obtained by a controllable hydrothermal conversion with the addition of $\left(\mathrm{NH}_{4}\right)_{2} \mathrm{CO}_{3}$. Based on characterizations on the evolution of morphology and composition with hydrothermal treatment time, we clarified the mechanism of this novel method as a dissolution-recrystallization process, as well as the effects of $\left(\mathrm{NH}_{4}\right)_{2} \mathrm{CO}_{3}$ concentration on the morphology and composition of particles. By changing concentrations and the ratio of the starting materials for nano-precipitation preparation, we achieved monotonic regulation on the size of the spherical particles, and the synthesis of $\mathrm{Ni}_{0.4} \mathrm{Co}_{0.2} \mathrm{Mn}_{0.4} \mathrm{CO}_{3}$ and $\mathrm{Ni}_{0.5} \mathrm{Co}_{0.2} \mathrm{Mn}_{0.3} \mathrm{CO}_{3}$, respectively. In addition, the spherical particles with a core-shell structure were preliminarily verified to be available by introducing nano-precipitates with different compositions in the hydrothermal treatment in sequence.
\end{abstract}

Keywords: Ni-Co-Mn carbonate; nanoparticle; spherical particle; microreaction technology; hydrothermal treatment

\section{Introduction}

$\mathrm{LiCoO}_{2}$ has been widely used as a positive electrode material in commercial lithium-ion batteries because of its high capacity, as well as excellent stability [1]. However, cobalt also causes serious problems, such as high price and environmental concerns. Alternatively, a promising material is $\mathrm{Li}\left[\mathrm{Ni}_{\mathrm{x}} \mathrm{Co}_{\mathrm{y}} \mathrm{Mn}_{1-\mathrm{x}-\mathrm{y}}\right] \mathrm{O}_{2}$ with a layered structure, which is considered to be one of the best replacements for $\mathrm{LiCoO}_{2}$ for hybrid electric vehicle (HEV) power source systems [2-8]. Since this material has combined nickel, cobalt, and manganese together, it may show the advantages of these three metals in terms of thermal stability, rate capability, and safety at a proper composition. In detail, introducing Co can increase the stability of the structure and suppress the cation mixing, while too much Co causes capacity loss; increasing the amount of $\mathrm{Ni}$ will be benefit the capacity of the material, but too much $\mathrm{Ni}$ leads to the cation mixing, which decreases the cycling stability; a proper amount of Mn can improve the safety, but too much Mn can change the structure from layered to spinel [9].

In general, researchers usually prepared $\mathrm{NiCoMn}(\mathrm{NCM})$ precursor (hydroxide or carbonate) and then combined it with lithium salt. Many studies have shown that the electrochemical performance of the final product strongly depends on the properties of the precursor, such as morphology [10-13], size of the primary and secondary particles [13-16], size distribution [17], composition [6,8,9,18-21], as well as structure $[22,23]$. Therefore, it is vital to control the precursor in order to obtain the materials with excellent performance, for which a simple and controlled preparation method is highly required. Until now, many methods have been developed, including co-precipitation $[4,11]$, the sol-gel method [24,25], the spray-dry method [5,18], the solid-state reaction [26], and others [27-30]. Among these methods, the most popular one is co-precipitation since it is relatively simple to implement $[4,31]$. 
The hydroxide precipitation has been widely investigated since it is much easier to produce the precursor with high content of nickel and cobalt [22,23,32]. Meanwhile, carbonate co-precipitation is good for producing Mn-rich material since $\mathrm{MnCO}_{3}$ is much more stable than $\mathrm{NiCO}_{3}$ and $\mathrm{CoCO}_{3}$ [33]. However, in the co-precipitation for producing hydroxide, $\mathrm{Mn}^{2+}$ is easy to be oxidized with an excess of $\mathrm{OH}^{-}$locally to change into $\mathrm{MnOOH}$ and $\mathrm{MnO}_{2}$, so it is hard to strictly control the stoichiometric ratio of the cathode material. On the other hand, in the co-precipitation for producing carbonate, $\mathrm{Mn}^{2+}$ could be fixed by $\mathrm{CO}_{3}^{2-}$ and would not be changed during the reaction. Thus, we do not have to provide an atmosphere without oxygen, and carbonate co-precipitation is a competitive method for industrial application.

High volumetric energy density is highly desired for the lithium ion batteries used in electric vehicles. The uniform distribution of spherical powders with high tap-density is the key for the application of NCM material [34]. Many studies have been working on the tap density of powder materials which depends highly on their morphology, size, and size distribution [35,36]. As is well known, irregular morphology of particles could cause a bridging phenomenon to decrease the tap density, and preparing spherical particles at micron size is an effective way to improve the volumetric energy density of cathode materials. Moreover, spheres have excellent flow, dispersion, and processing performance, which is beneficial for their applications.

However, the direct co-precipitation is a fast process that can produce a large number of nuclei simultaneously, for which it is difficult to obtain spherical particles at micron size and control the composition of $\mathrm{Ni}, \mathrm{Co}$, and $\mathrm{Mn}$ accurately. Aiming at these problems, researchers usually use a simultaneous dripping method with a chelating agent. The dripping process is always very slow, during which controlling the synthesis condition strictly is still a difficult and tedious task $[4,17,37]$. The hydrothermal method could also prepare NiCoMn precursors at micron size, but it is difficult to control the morphology of particles and the starting materials are relatively expensive [38,39]. So far, the preparation of carbonate precursor by using hydrothermal treatment has been rarely reported.

Herein, we provide a novel and controllable method combining microreaction technology and hydrothermal treatment together for preparing $\mathrm{Ni}-\mathrm{Co}-\mathrm{Mn}$ carbonate precursor spheres at micron size. In detail, firstly, primary homogeneous $\mathrm{Ni}-\mathrm{Co}-\mathrm{Mn}$ carbonate nanoparticles were obtained by using a microreactor, an effective tool for carrying out nanoprecipitation due to its high mixing efficiency [40-43]. Then, hydrothermal treatment was exploited to convert primary precipitates to the spherical Ni-Co-Mn carbonate particles with the existence of ammonium carbonate. On the basis of understanding the process and mechanism, we achieved the controlled synthesis of precursors with different sizes and composition, and investigated the possibility of preparing core-shell materials as well.

\section{Results and Discussion}

\subsection{Synthesis and Characterization of $\mathrm{Ni}_{1 / 3} \mathrm{Co}_{1 / 3} \mathrm{Mn}_{1 / 3} \mathrm{CO}_{3}$}

We characterized the products by scanning electron microscopy (SEM) (HITACHI, Tokyo, Japan), X-ray diffraction (XRD) (Bruker, Karlsruhe, Germany), as well as inductively-coupled plasma (ICP) (ThermoFisher, Walham, MA, USA) to confirm the effectiveness of our method in preparing carbonate precipitates with desired composition and morphology. Figure 1 shows the SEM images of $\mathrm{Ni}_{1 / 3} \mathrm{Co}_{1 / 3} \mathrm{Mn}_{1 / 3} \mathrm{CO}_{3}$ before and after hydrothermal treatment, respectively. As seen, the hydrothermal treatment can change the morphology completely. Before hydrothermal treatment, the precipitates are irregular agglomerates of sphere-like nanoparticles with the size of around $15 \mathrm{~nm}$. After hydrothermal treatment, we obtained uniform spherical particles with an average size of 3-4 $\mu \mathrm{m}$. The high-resolution SEM image shows these spherical particles at micron size are composed of cubic nanoparticles with the size of less than $100 \mathrm{~nm}$. The ICP characterization indicates the ratio of the metallic elements in average is $\mathrm{Ni}: \mathrm{Co}: \mathrm{Mn}=0.30: 0.34: 0.36$, similar with the element ratio in the starting materials used for primary nano-precipitates preparation. 


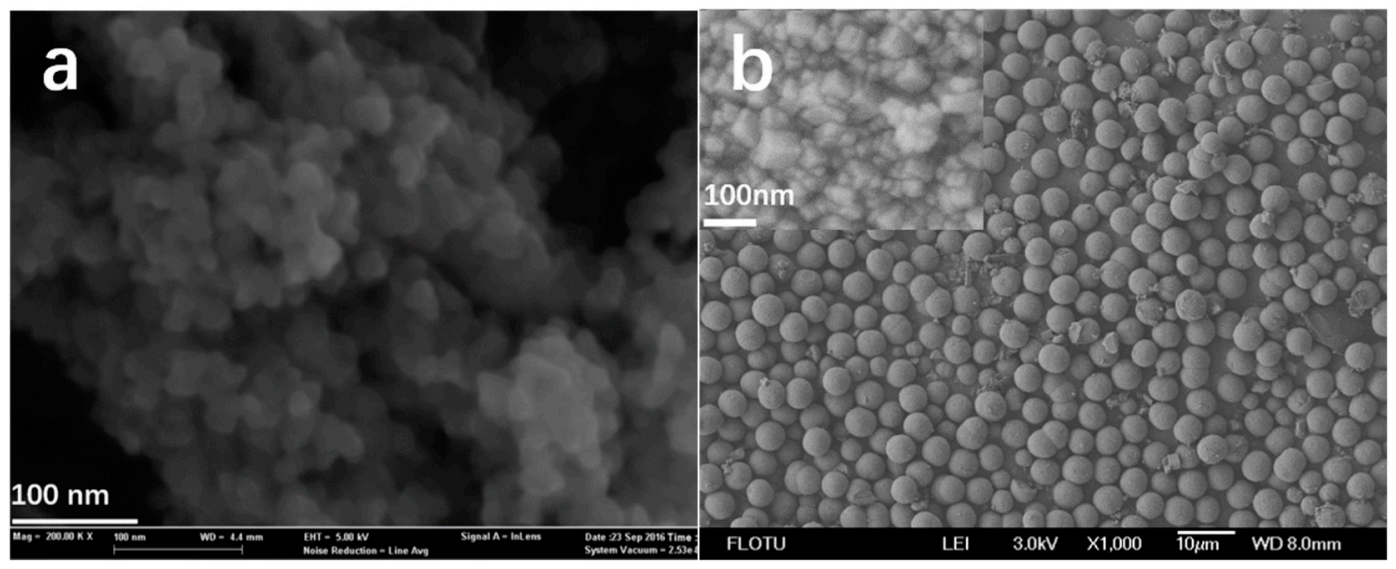

Figure 1. SEM images of the precipitates (a) before and (b) after hydrothermal treatment. The ratio of starting material, $R_{\mathrm{M}}=1: 1: 1$ (Ni:Co:Mn); the total concentration of metals, $C_{\mathrm{M}}=0.15 \mathrm{~mol} \cdot \mathrm{L}^{-1}$; the concentration of ammonia carbonate, $C_{(\mathrm{NH} 4) 2 \mathrm{CO} 3}=0.15 \mathrm{~mol} \cdot \mathrm{L}^{-1}$; and the temperature of hydrothermal treatment, $T_{\mathrm{h}}=180^{\circ} \mathrm{C} ; t_{\mathrm{h}}=24 \mathrm{~h}$.

Figure 2 shows the XRD patterns of $\mathrm{Ni}_{1 / 3} \mathrm{Co}_{1 / 3} \mathrm{Mn}_{1 / 3} \mathrm{CO}_{3}$ before and after hydrothermal treatment. Obviously, these two patterns are totally different, indicating that the precipitated sample is amorphous and, upon hydrothermal treatment, a crystalline material is obtained. Additionally, the pattern of the precipitates after hydrothermal is quite consistent with ideal $\mathrm{MnCO}_{3}$ and also shows broad integrated lines which can be attributed to the mix of $\mathrm{NiCO}_{3}, \mathrm{CoCO}_{3}$, and $\mathrm{MnCO}_{3}$. Figure 3 is the mapping of a single particle presenting the elemental distribution. The yellow, red, and blue dots represent the distributions of $\mathrm{Ni}, \mathrm{Co}$, and $\mathrm{Mn}$, respectively. The brigthness of the color reflects the intensity of the element signal. Uniform brightness distribution reflects the composition distribution of the spherical precipates is uniform. According to these results, we could confirm that it is feasible to prepare spherical carbonate precursor at micron size with the same element ratio as the starting materials by the method combining microreaction technolgy with hydrothermal treatment.

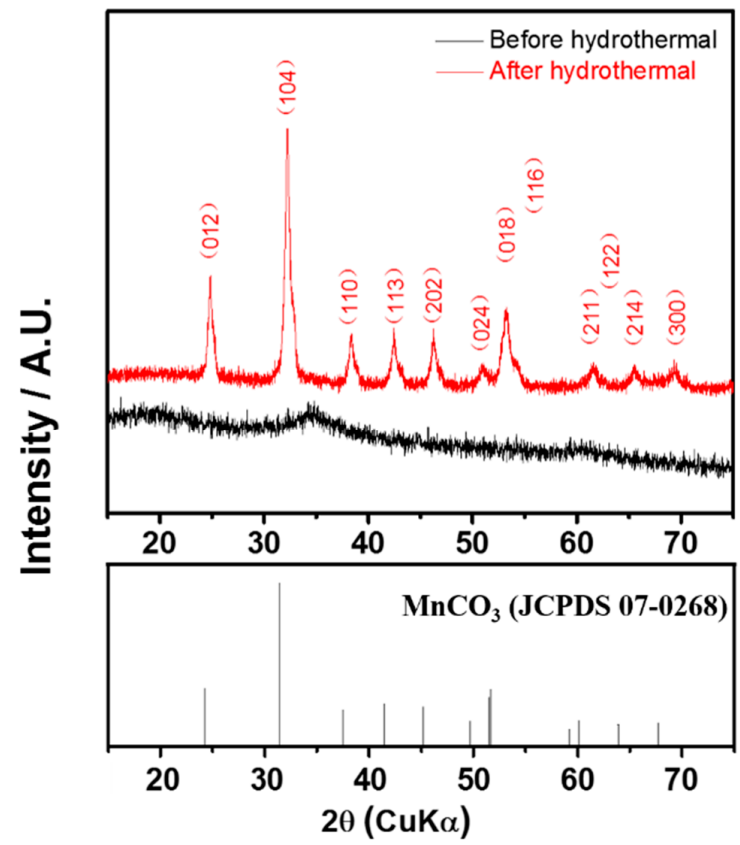

Figure 2. X-ray diffraction patterns for the precipitates before and after hydrothermal treatment. $R_{\mathrm{M}}=1: 1: 1(\mathrm{Ni}: \mathrm{Co}: \mathrm{Mn}) ; \mathrm{C}_{\mathrm{M}}=0.15 \mathrm{~mol} \cdot \mathrm{L}^{-1} ; \mathrm{C}_{(\mathrm{NH} 4) 2 \mathrm{CO} 3}=0.15 \mathrm{M} ; \mathrm{T}_{\mathrm{h}}=180{ }^{\circ} \mathrm{C} ; t_{\mathrm{h}}=24 \mathrm{~h}$. 


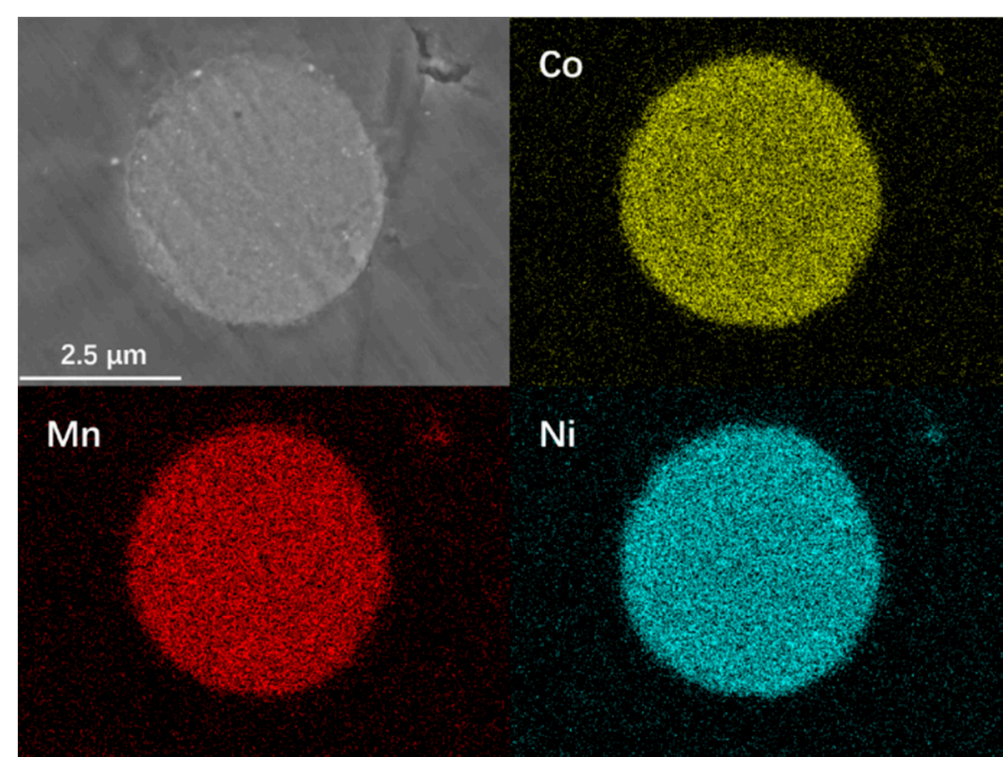

Figure 3. SEM-EDX mapping photographs for $\mathrm{Ni}, \mathrm{Co}$, and $\mathrm{Mn}$ in products after hydrothermal treatment. $R_{\mathrm{M}}=1: 1: 1(\mathrm{Ni}: \mathrm{Co}: \mathrm{Mn}) ; \mathrm{C}_{\mathrm{M}}=0.15 \mathrm{~mol} \cdot \mathrm{L}^{-1} ; \mathrm{C}_{(\mathrm{NH}) 2 \mathrm{CO} 3}=0.15 \mathrm{~mol} \cdot \mathrm{L}^{-1} ; T_{\mathrm{h}}=180{ }^{\circ} \mathrm{C} ; \mathrm{t}_{\mathrm{h}}=24 \mathrm{~h}$.

\subsection{Synthesis Mechanism}

Hydrothermal treament commonly leads to a complex dissolution-recrystallization process determined by many factors, such as temperature, composition of solution, reaction time, and so on. In order to understand the details of reaction mechanism, we attempted to investigate the effects of these factors separately. Figure 4 shows the SEM images of products after hydrothermal treatment with different time. Evidently, the evolution of the morphology of the products is significant. The products after $24 \mathrm{~h}$ hydrothermal treatment (Figure $4 \mathrm{~d}$ ) have relatively uniform size and very smooth surfaces. Comparatively, for the products after $3 \mathrm{~h}, 6 \mathrm{~h}$, or $9 \mathrm{~h}$ hydrothermal treament, there exist many large particles composed of irregular blocks. The energy dispersive spectroscopic (EDS) (Zeiss, Oberkochen, Germany) characterization shows that the main components of these blocks are Ni and Co. The general tendency is that the size distribution of particles becomes uniform and these large particles dimish gradually with the proceeding of hydrothermal treatment. We also noticed that the solution above the products is always purple, whaterever the hydrothermal treatment time is $3 \mathrm{~h}, 6 \mathrm{~h}$, or $9 \mathrm{~h}$. However, it becomes almost colorless after $24 \mathrm{~h}$ hydrothermal treatment. The color of the solution indicates the existence of metal ions in the solution. These phenomena imply that the evolution of morphology surely carries out via a dissolution process. Since the blocks settled on the surface of spherical particles present a different appearance or size compared with the precipitates and the microblocks composing spherical particles, they might come from the cooling crystallization of metal carbonates from solution. Thus, the small content of $\mathrm{Mn}$ in the blocks may be determined the small content of $\mathrm{Mn}$ in the solution. Correspondingly, according to the stability contants of different metal ammonia complexes, the order of the metal contents in solution is just $\mathrm{Ni}>\mathrm{Co}>\mathrm{Mn}$. However, monitoring the evolutions of $\mathrm{pH}$ and the ions constributions during hydrothermal treatment could help us understand the mechanism in depth and is worth further investigation.

Figure 5 shows the effects of the concentration of $\left(\mathrm{NH}_{4}\right)_{2} \mathrm{CO}_{3}$ in hydrothermal treatment. As seen, without the addition of $\left(\mathrm{NH}_{4}\right)_{2} \mathrm{CO}_{3}$, the products are mainly of irregular bulk precipitates with rough surfaces. When $0.05 \mathrm{~mol} \cdot \mathrm{L}^{-1}\left(\mathrm{NH}_{4}\right)_{2} \mathrm{CO}_{3}$ was added, there are some rough spheres surrounded by many blocks (Figure 5b), and the components of these blocks are also mainly $\mathrm{Ni}$ and $\mathrm{Co}$. As increasing the concentration of $\left(\mathrm{NH}_{4}\right)_{2} \mathrm{CO}_{3}$ to $0.10 \mathrm{~mol} \cdot \mathrm{L}^{-1}$, these blocks become smaller, but still larger than $100 \mathrm{~nm}$. Figure 6 shows SEM mapping photographs of Ni, Co, and Mn corresponding to the products in Figure $5 \mathrm{c}$. The signals of $\mathrm{Ni}$ and $\mathrm{Co}$ are very intensive in the surface layer of the spherical particle, and in 
the core the distributions of $\mathrm{Ni}, \mathrm{Co}$, and $\mathrm{Mn}$ are much uniform. It could be reasonably assumed that the environments for generating the core (smooth spheres) and the surface layer (irregular blocks) are quite different. By adding $0.15 \mathrm{~mol} \cdot \mathrm{L}^{-1}$ of $\left(\mathrm{NH}_{4}\right)_{2} \mathrm{CO}_{3}$, the blocks almost dissapeared and we fortunately obtained uniform and smooth spherical particles with average size of 3-4 $\mu \mathrm{m}$ and the primary particle is less than $100 \mathrm{~nm}$. However, when the concentration of $\left(\mathrm{NH}_{4}\right)_{2} \mathrm{CO}_{3}$ was increased to $0.25 \mathrm{~mol} \cdot \mathrm{L}^{-1}$ and $0.3 \mathrm{~mol} \cdot \mathrm{L}^{-1}$, and the particles are still smooth, but their size distributions become wider.
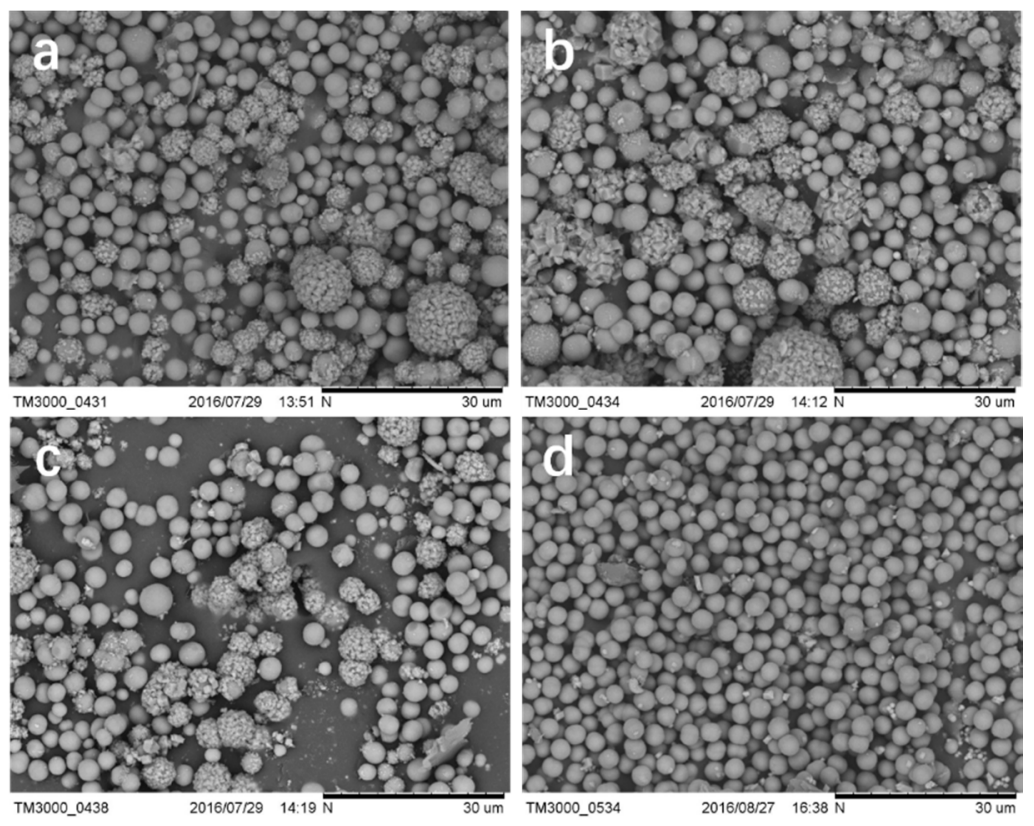

Figure 4. SEM images of the products after hydrothermal treatments with different time $\left(t_{\mathrm{h}}\right) .(\mathrm{a}) 3 \mathrm{~h}$; (b) $6 \mathrm{~h}$; (c) $9 \mathrm{~h}$; and (d) $24 \mathrm{~h} . R_{\mathrm{M}}=1: 1: 1(\mathrm{Ni}: \mathrm{Co}: \mathrm{Mn}) ; C_{\mathrm{M}}=0.15 \mathrm{~mol} \cdot \mathrm{L}^{-1} ; C_{(\mathrm{NH} 4) 2 \mathrm{CO} 3}=0.15 \mathrm{~mol} \cdot \mathrm{L}^{-1}$; and $T_{\mathrm{h}}=180^{\circ} \mathrm{C}$.
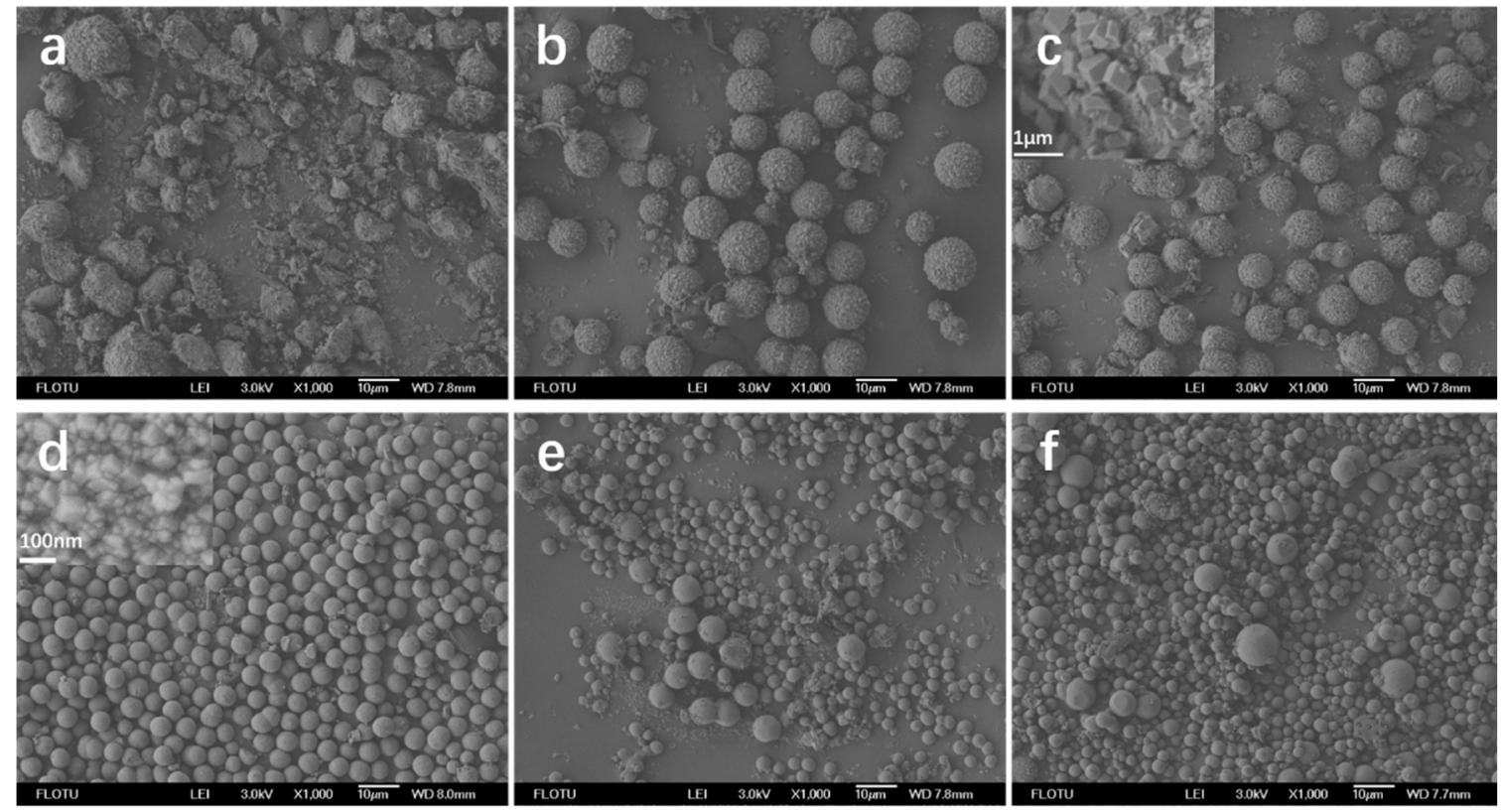

Figure 5. SEM images of the products after hydrothermal treatment in ammonia carbonate of different concentration $\left(C_{(\mathrm{NH} 4) 2 \mathrm{CO} 3}\right)$. (a) $0 \mathrm{~mol} \cdot \mathrm{L}^{-1}$; (b) $0.05 \mathrm{~mol} \cdot \mathrm{L}^{-1}$; (c) $0.10 \mathrm{~mol} \cdot \mathrm{L}^{-1}$; (d) $0.15 \mathrm{~mol} \cdot \mathrm{L}^{-1}$; (e) $0.25 \mathrm{~mol} \cdot \mathrm{L}^{-1}$; (f) $0.30 \mathrm{~mol} \cdot \mathrm{L}^{-1} \cdot R_{\mathrm{M}}=1: 1: 1(\mathrm{Ni}: \mathrm{Co}: \mathrm{Mn}) ; T_{\mathrm{h}}=180{ }^{\circ} \mathrm{C}$; and $t_{\mathrm{h}}=24 \mathrm{~h}$. 

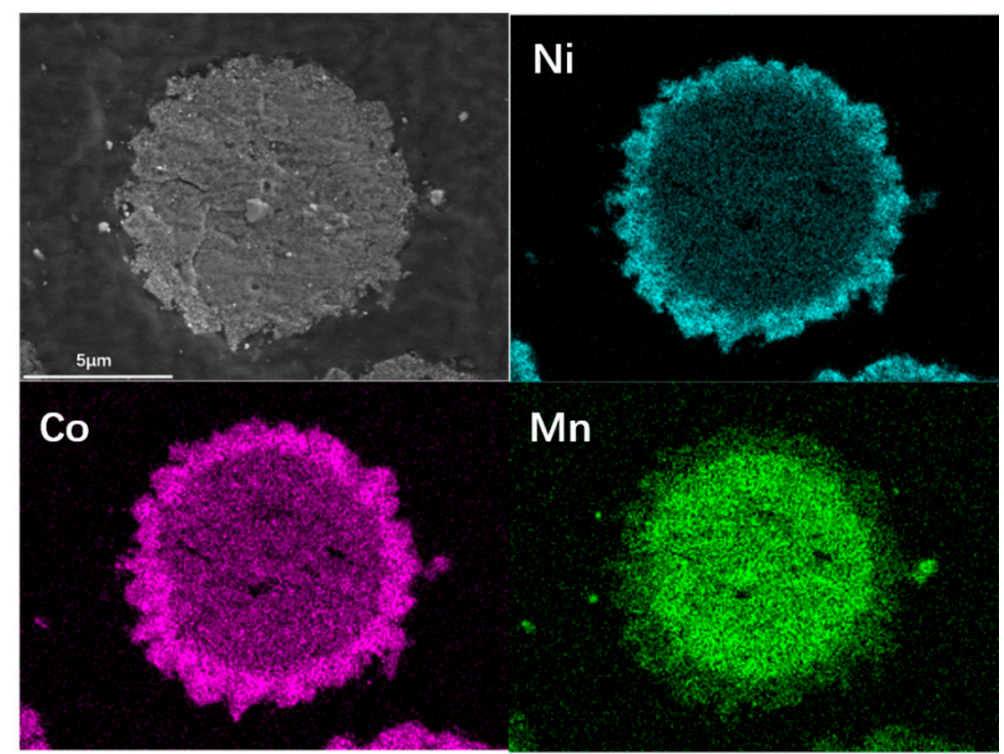

Figure 6. SEM-EDX mapping photograph for $\mathrm{Ni}, \mathrm{Co}$ and $\mathrm{Mn}$ in a single particle obtained by hydrothermal treatment. $R_{\mathrm{M}}=1: 1: 1(\mathrm{Ni}: \mathrm{Co}: \mathrm{Mn}) ; \mathrm{C}_{(\mathrm{NH} 4) 2 \mathrm{CO} 3}=0.1 \mathrm{~mol} \cdot \mathrm{L}^{-1} ; T_{\mathrm{h}}=180^{\circ} \mathrm{C} ;$ and $t_{\mathrm{h}}=24 \mathrm{~h}$.

Herein, we proposed a schematic mechanism, as shown in Figure 7, to explain the experimental results based on following three facts: (1) the primary nano-precipitates could partly dissolve in solution; (2) the spherical particles are composed of nanocrystals as the secondary precipitates with crystalline structure different from the primary nano-precipitates; (3) $\left(\mathrm{NH}_{4}\right)_{2} \mathrm{CO}_{3}$ has remarkable influences on both the dissolution and recrystallization processes. We suppose that the nanocrystals have good thermodynamics stability compared with the primary nano-precipiates and the $\left(\mathrm{NH}_{4}\right)_{2} \mathrm{CO}_{3}$ in solution could dissociate to release $\mathrm{NH}_{3}$ to accelearte the conversion between them $[4,38,44]$. The conversion process includes following steps: (1) the primary nano-precipitates dissolve into solution partly to increase the contents of metals in solution to relatively high levels; (2) the nuclei of secondary precipitates generate and grow up to nanocrystals in solution, during which the dissolution of the primary nano-precipitates continue to proceed; (3) the nanocrytals gradually aggregate to lead to the generation and growth of spherical particles in solution; and (4) as all the primary precipitates are consumed, the contents of metals in solution will decrease until the recrystalization process terminates due to the limitation on thermodynamics equilibrium.

The addtion of $\left(\mathrm{NH}_{4}\right)_{2} \mathrm{CO}_{3}$ could increase the contents of metals in solution, as well as the conversion rate from primary nanoprecipitates to nanocrystals. Due to the difference of $\mathrm{Ni}, \mathrm{Co}$, and $\mathrm{Mn}$ in complexation ability with $\mathrm{NH}_{3}$, the contents of $\mathrm{Ni}$ and $\mathrm{Co}$ are much higher than that of $\mathrm{Mn}$. As $\left(\mathrm{NH}_{4}\right)_{2} \mathrm{CO}_{3}$ is in absence, the conversion is so slow that after $24 \mathrm{~h}$ hydrothermal treatment plenty of nanoprecipitates still exist and spherical particles are seldom seen. As $\left(\mathrm{NH}_{4}\right)_{2} \mathrm{CO}_{3}$ being at low concentration, after $24 \mathrm{~h}$ hydrothermal treatment part of conversion could be achieved to generate spherical particles. However, the contents of metals in solution ( $\mathrm{Ni}$ and Co take the majority) may be still at high levels, which could separated out as $\mathrm{MCO}_{3}$ in the cooling period before sampling. As the concentration of $\left(\mathrm{NH}_{4}\right)_{2} \mathrm{CO}_{3}$ being high enough, $24 \mathrm{~h}$ hydrothermal treatment can deplete the primary precipitates. Meanwhile, with the increase of the concentration of $\left(\mathrm{NH}_{4}\right)_{2} \mathrm{CO}_{3}$, more nuclei could generate in solution, which will inhibit the growth and aggregation of nanocrystals to increase the size of nanocrystals and the size of their aggregation; the conversion rate will increase to make the growth and aggregation of nanocrystals easy to get out of control, and it will broaden the size distribution of the final products. Nevertheless, the control on the growth and aggregation of nanocrystals, as well as the optimization of $\left(\mathrm{NH}_{4}\right)_{2} \mathrm{CO}_{3}$ concentration, are worthy of further investigations. 

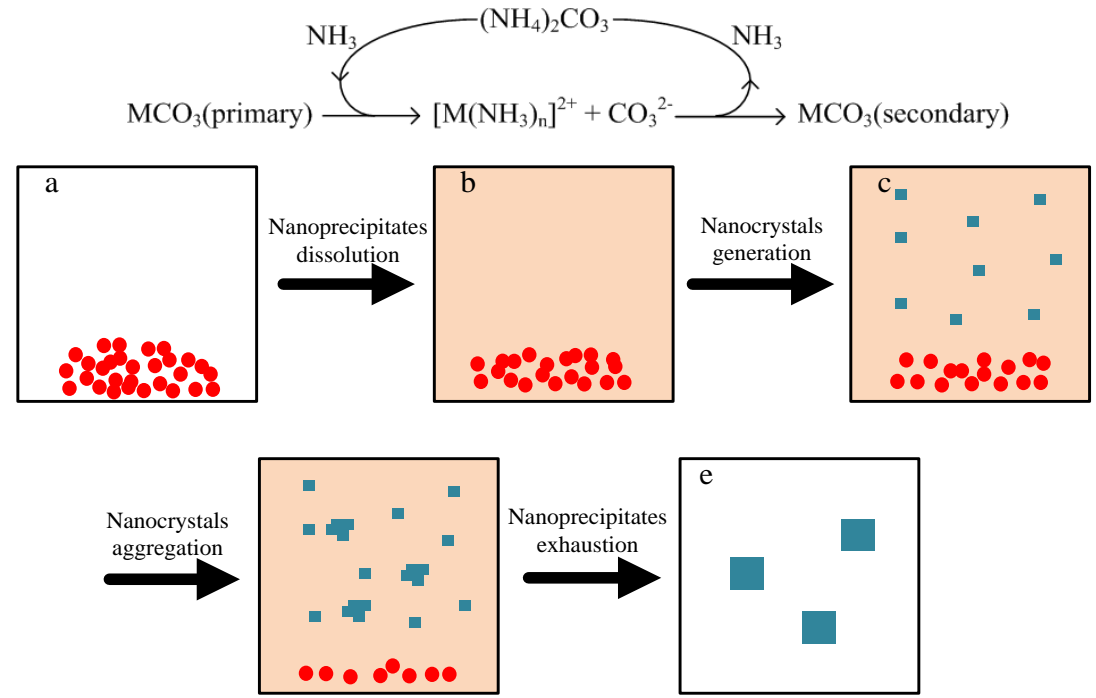

Figure 7. The proposed mechanism for the synthesis of NCM carbonate spheres. The red circles and the blue squares indicate primary nano-precipitates and nanocrystals as the secondary precipitates, respectively.

\subsection{Regulations on the Size and Composition}

According to the synthesis mechanism metioned above, if we added more primary nanoprecipitates into the autoclave, more metals will be provided for generating larger spherical particles. Therefore, we attempted to tune the size of the final products by changing the concentrations of the starting materials used for primary nanoprecipitate preparation. As seen in Figure 8, when the total concentration of metals $\left(C_{\mathrm{M}}\right)$ is $0.15 \mathrm{~mol} \cdot \mathrm{L}^{-1}$, the average size of final products is $3.39 \mu \mathrm{m}$. When we increased $C_{\mathrm{M}}$, the average size becomes $3.95 \mu \mathrm{m}$ at $C_{\mathrm{M}}=0.30 \mathrm{~mol} \cdot \mathrm{L}^{-1}$ and $4.76 \mu \mathrm{m}$ $C_{\mathrm{M}}=0.6 \mathrm{~mol} \cdot \mathrm{L}^{-1}$. The size of the particles only increases with the increasing of $C_{\mathrm{M}}$, but it does abide by the proportional relation. A possible reason is that more nuclei may be generated in the initial period due to the acceleration of nanoprecipitate dissolution [45]. It can also explain why the size distribution of final product becomes wider with the increase in concentration.
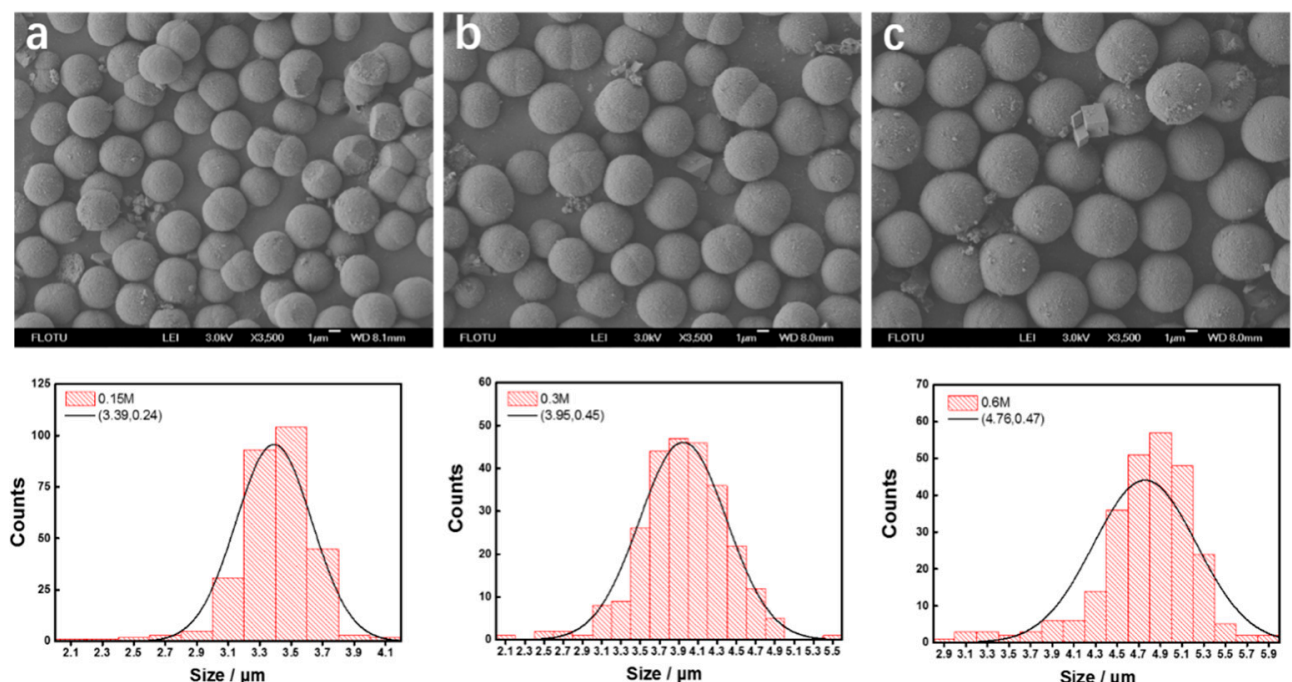

Figure 8. SEM images and size distributions of the products after hydrothermal treatment when using starting materials at different concentration $\left(C_{\mathrm{M}}\right)$. (a) $0.15 \mathrm{~mol} \cdot \mathrm{L}^{-1}$; (b) $0.3 \mathrm{~mol} \cdot \mathrm{L}^{-1}$; (c) $0.6 \mathrm{~mol} \cdot \mathrm{L}^{-1}$. $R_{\mathrm{M}}=1: 1: 1(\mathrm{Ni}: \mathrm{Co}: \mathrm{Mn}) ; \mathrm{C}_{(\mathrm{NH} 4) 2 \mathrm{CO} 3}=0.15 \mathrm{~mol} \cdot \mathrm{L}^{-1} ; \mathrm{T}_{\mathrm{h}}=180{ }^{\circ} \mathrm{C} ;$ and $t_{\mathrm{h}}=24 \mathrm{~h}$. 
As is well known, dissolution-recrystallization process can only change the morphology and structure of particles. The composition cannot be changed without the addition of other reageants. Inspired by this recognition, we also prepared precursors $\mathrm{Ni}_{0.4} \mathrm{Co}_{0.2} \mathrm{Mn}_{0.4} \mathrm{CO}_{3}$ and $\mathrm{Ni}_{0.5} \mathrm{Co}_{0.2} \mathrm{Mn}_{0.3} \mathrm{CO}_{3}$ by changing the ratio of metals in starting materials for primary nanoprecipitates preparation. The morphology of the products was characterized by SEM. As is seen in Figure 9, all three products are of spherical particles. Their compositions were determined by ICP, and are shown in Table 1. The amount of $\mathrm{Ni}$ is always slightly lower than the ratio of the starting materials, but, in general, the determined compositions agree well with that of the starting materials. The deviation of Ni content may be attributed to the strong complexation ability between $\mathrm{Ni}$ and $\mathrm{NH}_{3}$. As a result, the residual amount of $\mathrm{Ni}$ in the solution was the greatest, so the amount of $\mathrm{Ni}$ in the solid products is the least.
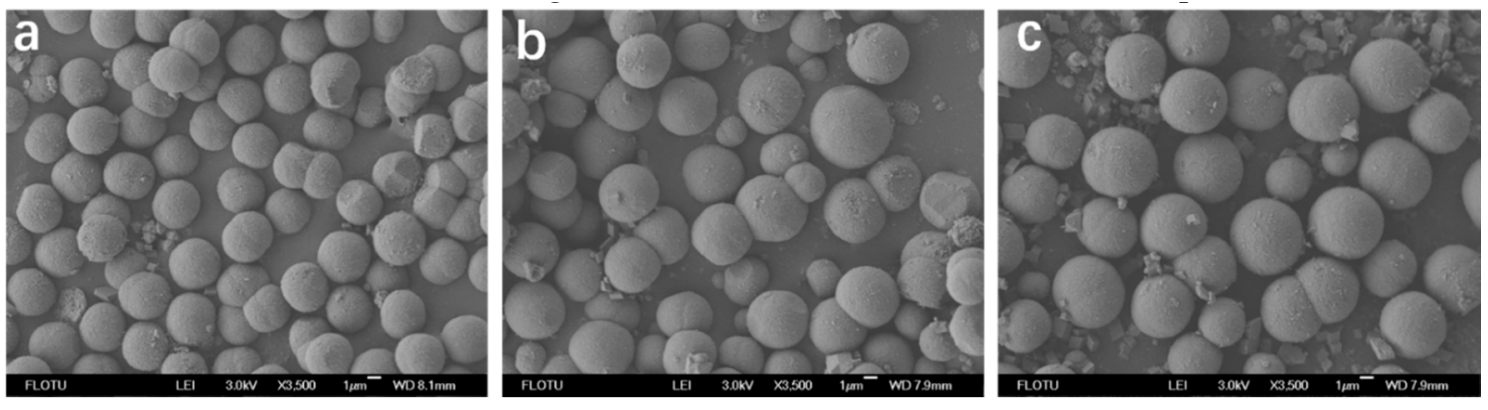

Figure 9. SEM images of products when using starting materials at different ratio $\left(R_{\mathrm{M}}\right)$. (a) Ni:Co:Mn $=1: 1: 1 ;(b) \mathrm{Ni}: \mathrm{Co}: \mathrm{Mn}=4: 2: 4 ;(\mathbf{c}) \mathrm{Ni}: \mathrm{Co}: \mathrm{Mn}=5: 2: 3 . C_{\mathrm{M}}=15 \mathrm{~mol} \cdot \mathrm{L}^{-1} ; C_{(\mathrm{NH} 4) 2 \mathrm{CO} 3}=0.15 \mathrm{~mol} \cdot \mathrm{L}^{-1}$; $T_{\mathrm{h}}=180^{\circ} \mathrm{C}$; and $t_{\mathrm{h}}=24 \mathrm{~h}$.

Table 1. Element compositions of products when using starting materials at different ratios.

\begin{tabular}{clccc}
\hline \multirow{2}{*}{ Ratio of Starting Materials } & \multirow{2}{*}{ Expected Formula } & \multicolumn{3}{c}{ Determined Compositions } \\
\cline { 3 - 5 } & & Ni & Co & Mn \\
\hline Ni:Co:Mn $=1: 1: 1$ & $\mathrm{Ni}_{1 / 3} \mathrm{Co}_{1 / 3} \mathrm{Mn}_{1 / 3} \mathrm{CO}_{3}$ & 0.2958 & 0.3411 & 0.3631 \\
$\mathrm{Ni}: \mathrm{Co}: \mathrm{Mn}=4: 2: 4$ & $\mathrm{Ni}_{0.4} \mathrm{Co}_{0.2} \mathrm{Mn}_{0.4} \mathrm{CO}_{3}$ & 0.3819 & 0.2042 & 0.4139 \\
$\mathrm{Ni}: \mathrm{Co}: \mathrm{Mn}=5: 2: 3$ & $\mathrm{Ni}_{0.5} \mathrm{Co}_{0.2} \mathrm{Mn}_{0.3} \mathrm{CO}_{3}$ & 0.4968 & 0.2042 & 0.2990 \\
\hline
\end{tabular}

Reently, the cathode materials with core-shell structures have been drawing more attention [22,46,47], since the core-shell structures may restrict the formation of solid electrolyte interphase and volume expansion. Our method of combining nanoprecipitate dissolution with nanocrystal growth and aggregation may also be applied in preparing spherical particles with core-shell structures, as we introduce the nanoprecipitates with different compositions in hydrothermal treatments in sequence. Figure 10 shows the mapping of the obtained spherical particles with a core-shell structure. The synthesis procedures are illustrated in the context. Herein, the core is $\mathrm{Ni}_{1 / 3} \mathrm{Co}_{1 / 3} \mathrm{Mn}_{1 / 3} \mathrm{CO}_{3}$, and the shell is Co. The green image is the mapping of cobalt. We can see a light circle around the surface of the particle, which means the content of Co in the surface layer is higher than that in the core. Figure 11 shows the energy dispersive spectroscopic (EDS) of the core-shell structure. The line scan was done at the white line in Figure 1a. From the images, we can see that the Co element is in abundance at the surface. Therefore, we can confirm, preliminarily, that the core-shell structure has been obtained. 


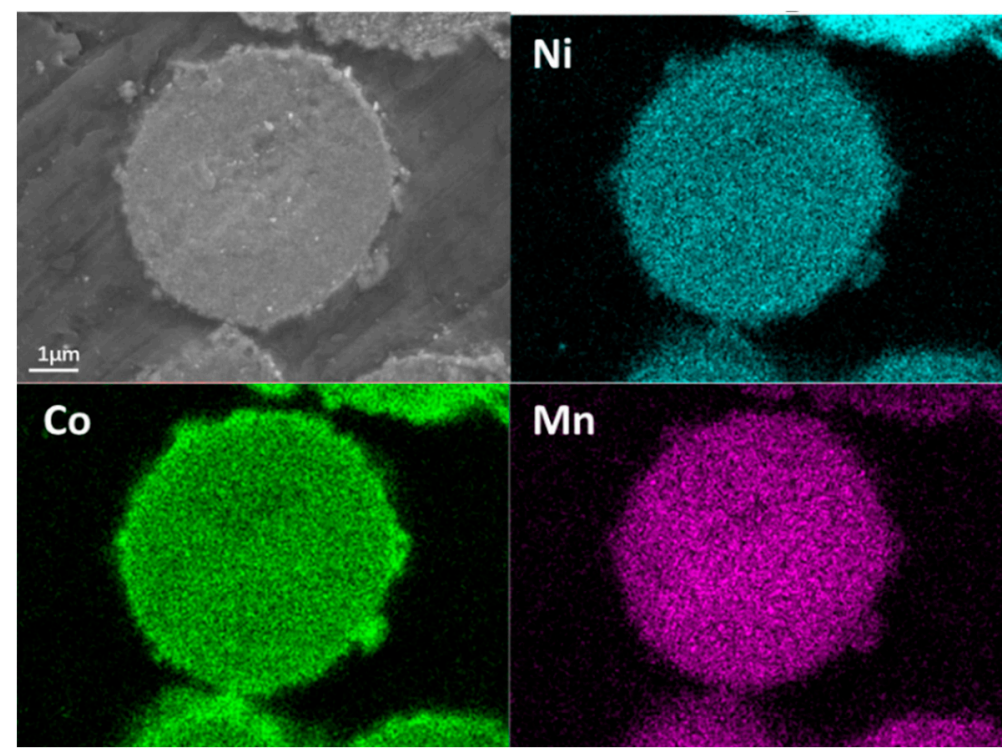

Figure 10. SEM mapping images of particles with a core-shell structure.

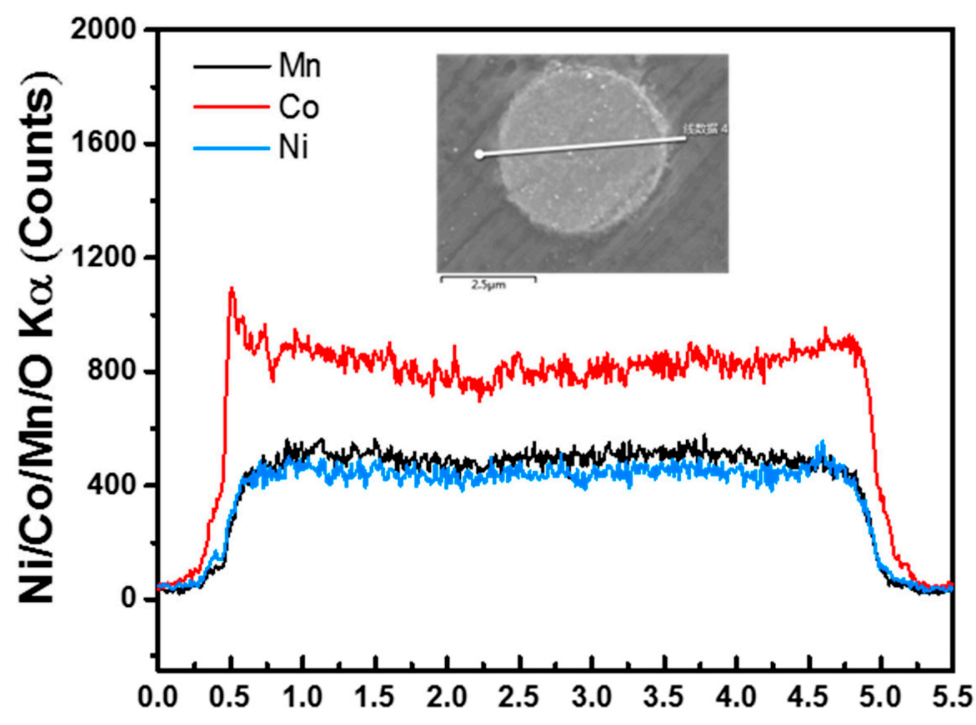

Distance from the start point, $\mu \mathrm{m}$

Figure 11. The EDS images of the particles with a core-shell structure.

\section{Materials and Methods}

All of the reagents used during the experiments, including cobalt sulfate heptahydrate $\left(\mathrm{CoSO}_{4} \cdot 7 \mathrm{H}_{2} \mathrm{O}, 99.5 \%\right)$, nickel sulfate hexahydrate $\left(\mathrm{NiSO}_{4} \cdot 6 \mathrm{H}_{2} \mathrm{O}, 99 \%\right)$, manganese sulfate monohydrate $\left(\mathrm{MnSO}_{4} \cdot \mathrm{H}_{2} \mathrm{O}, 99 \%\right)$, ammonium carbonate, sodium carbonate, and ethanol, were of analytical reagent grade. $\mathrm{CoSO}_{4} \cdot 7 \mathrm{H}_{2} \mathrm{O}, \mathrm{NiSO}_{4} \cdot 6 \mathrm{H}_{2} \mathrm{O}$, and $\mathrm{MnSO}_{4} \cdot \mathrm{H}_{2} \mathrm{O}$ were purchased from J\&K Scientific (Beijing, China). Ammonium carbonate and sodium carbonate were purchased from West Long Chemical Co., Ltd. (Shantou, China). Ethanol was obtained from Beijing Tong Guang Fine Chemicals Company (Beijing, China). All of the chemicals were used without any further purification. Furthermore, the deionized water was used to make up solutions throughout the experiments.

The precursor was synthesized by two steps as shown in Figure 12. The first step is to obtain homogeneous nanoparticles by using a home-made microreactor. The geometric size of the microchannel was $15 \mathrm{~mm} \times 0.5 \mathrm{~mm} \times 0.5 \mathrm{~mm}$ (length $\times$ width $\times$ height). A stainless steel 
membrane with an average pore diameter of $5 \mu \mathrm{m}$ was used as the dispersion medium. We chose $\mathrm{Ni}_{1 / 3} \mathrm{Co}_{1 / 3} \mathrm{Mn}_{1 / 3} \mathrm{CO}_{3}$ as an example to describe the experimental procedures: (1) the dispersed fluid containing $0.1 \mathrm{M} \mathrm{CoSO}_{4}, 0.1 \mathrm{M} \mathrm{NiSO}_{4}$, and $0.1 \mathrm{M} \mathrm{MnSO}_{4}$ was mixed with the continuous fluid containing $0.4 \mathrm{M} \mathrm{Na}_{2} \mathrm{CO}_{3}$ in the microreactor, and both of them were delivered by pumps at the flow rate of $40 \mathrm{~mL} / \mathrm{min}$; (2) the slurry containing primary nanoprecipitate $\mathrm{Ni}_{1 / 3} \mathrm{Co}_{1 / 3} \mathrm{Mn}_{1 / 3} \mathrm{CO}_{3}$ was generated and transferred into a $100 \mathrm{~mL}$ Telfon-lined stainless steel autoclave; (3) $0.3 \mathrm{M}\left(\mathrm{NH}_{4}\right)_{2} \mathrm{CO}_{3}$ at equal volume was added in the autoclave for hydrothermal treatment at $180{ }^{\circ} \mathrm{C}$; (4) after 24 hours, the final precipitates were separated from the solution by centrifugation, washed with deionized water and ethanol several times, and dried in an oven at $120{ }^{\circ} \mathrm{C}$ overnight. As for the $\mathrm{Ni}_{0.5} \mathrm{Co}_{0.2} \mathrm{Mn}_{0.3} \mathrm{CO}_{3}$ and $\mathrm{Ni}_{0.4} \mathrm{Co}_{0.2} \mathrm{Mn}_{0.4} \mathrm{CO}_{3}$, we just changed the ratio of the starting materials to prepare the primary nano-precipitates $\mathrm{Ni}_{0.5} \mathrm{Co}_{0.2} \mathrm{Mn}_{0.3} \mathrm{CO}_{3}$ and $\mathrm{Ni}_{0.4} \mathrm{Co}_{0.2} \mathrm{Mn}_{0.4} \mathrm{CO}_{3}$, respectively.

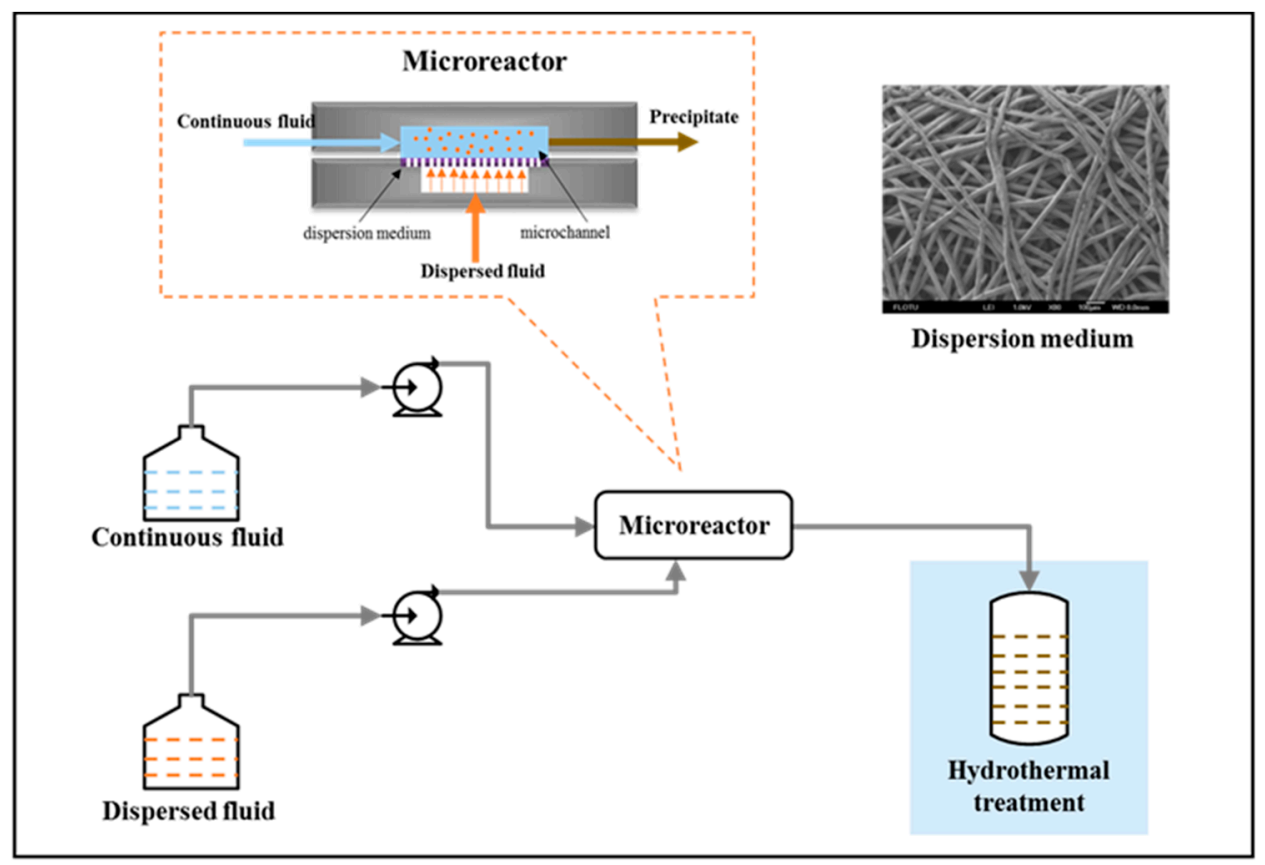

Figure 12. Schematic of the experimental process.

As for the core-shell structure, the final products without drying were transferred into autoclave as seeds. Then the slurry containing primary nanoprecipitate $\mathrm{CoCO}_{3}$ as the shell material obtained from the microreactor and $0.3 \mathrm{M}\left(\mathrm{NH}_{4}\right)_{2} \mathrm{CO}_{3}$ at equal volume were added into the autoclave for another hydrothermal treatment. The subsequent steps were the same. The samples used for EDS characterization were calcined at $500{ }^{\circ} \mathrm{C}$ in air for five hours.

The morphology of the prepared powders was observed by scanning electron microscope (SEM; JSM-7401, JEOL; HITACHI TM 3000, Tokyo, Japan). Element mapping and line scan were carried out by using a scanning electron microscope with an energy dispersive spectroscope (SEM; Merlin, ZEISS, Oberkochen, Germany). The phase of samples was characterized by X-ray diffraction (XRD; D8-Aduance, BRUKER, Karlsruhe, Germany) using $\mathrm{Cu} \mathrm{K} \alpha$ radiation ( $40 \mathrm{kV}$ and $40 \mathrm{~mA}$ ) at a scanning rate of $5^{\circ} \mathrm{min}^{-1}$. The element composition of the synthesized product was determined by an inductively-coupled plasma-optical emission spectroscope (ICP-OES; IRIS Intrepid II XSP SPS, Thermofisher, Walham, MA, USA).

\section{Conclusions}

In our work, starting from the preparation of Ni-Co-Mn carbonate nanoparticles by using microreaction technology, we proposed a simple and novel method to realize the controllable 
hydrothermal conversion from Ni-Co-Mn carbonate nanoparticles to uniform and spherical particles of $\mathrm{Ni}_{1 / 3} \mathrm{Co}_{1 / 3} \mathrm{Mn}_{1 / 3} \mathrm{CO}_{3}$ with the assistance of ammonia carbonate. Based on the systematic characterizations on evolutions of the morphology and composition with hydrothermal treatment time, we clarified the mechanism for this novel method as a dissolution-recrystallization process, as well as the effects of $\left(\mathrm{NH}_{4}\right)_{2} \mathrm{CO}_{3}$ concentration on the morphology and composition distribution. Furthermore, by changing the concentrations and the ratio of the starting materials for nano-precipitation preparation, we achieved monotonic regulation on the size of the spherical particles of $\mathrm{Ni}_{1 / 3} \mathrm{Co}_{1 / 3} \mathrm{Mn}_{1 / 3} \mathrm{CO}_{3}$, and the synthesis of $\mathrm{Ni}_{0.4} \mathrm{Co}_{0.2} \mathrm{Mn}_{0.4} \mathrm{CO}_{3}$ and $\mathrm{Ni}_{0.5} \mathrm{Co}_{0.2} \mathrm{Mn}_{0.3} \mathrm{CO}_{3}$, respectively. In addition, we preliminarily verified that the spherical particles with core-shell structure were available by introducing nanoprecipitates with different compositions in the hydrothermal treatment in sequence. The potential of this method in applications could be expected for the preparation of spherical particles with specially-designed profiles of composition due to its convenience and adaptability.

Acknowledgments: The authors are gratefully thankful for the support of the National Natural Science Foundation of China $(21176136,21422603)$ and National Basic Research Program of China (2007CB714302) on this work.

Author Contributions: Yangcheng Lu conceived and designed the experiments; Yanqing Tang performed the experiments; Yangcheng Lu, Yanqing Tan and Guangsheng Luo analyzed the data; Yangcheng Lu and Yanqing Tang wrote the paper.

Conflicts of Interest: The authors declare no conflict of interest.

\section{References}

1. Reimers, J.N.; Dahn, J.R. Electrochemical and in-situ $x$-ray-diffraction studies of lithium intercalation in lixcoo2. J. Electrochem. Soc. 1992, 139, 2091-2097. [CrossRef]

2. Ohzuku, T.; Makimura, Y. Layered lithium insertion material of $\mathrm{LiCo}_{1 / 3} \mathrm{Ni}_{1 / 3} \mathrm{Mn}_{1 / 3} \mathrm{O}_{2}$ for lithium-ion batteries. Chem. Lett. 2001, 642-643. [CrossRef]

3. Shaju, K.M.; Rao, G.V.S.; Chowdari, B.V.R. Performance of layered $\mathrm{Li}\left(\mathrm{Ni}_{1 / 3} \mathrm{Co}_{1 / 3} \mathrm{Mn}_{1 / 3}\right) \mathrm{O}_{2}$ as cathode for Li-ion batteries. Electrochim. Acta 2002, 48, 145-151. [CrossRef]

4. Lee, M.H.; Kang, Y.J.; Myung, S.T.; Sun, Y.K. Synthetic optimization of $\mathrm{Li}\left[\mathrm{Ni}_{1 / 3} \mathrm{Co}_{1 / 3} \mathrm{Mn}_{1 / 3}\right] \mathrm{O}_{2}$ via co-precipitation. Electrochim. Acta 2004, 50, 939-948. [CrossRef]

5. Park, S.H.; Yoon, C.S.; Kang, S.G.; Kim, H.S.; Moon, S.I.; Sun, Y.K. Synthesis and structural characterization of layered $\mathrm{Li}\left[\mathrm{Ni}_{1 / 3} \mathrm{Co}_{1 / 3} \mathrm{Mn}_{1 / 3}\right]_{2}$ cathode materials by ultrasonic spray pyrolysis method. Electrochim. Acta 2004, 49, 557-563. [CrossRef]

6. Liu, Z.L.; Yu, A.S.; Lee, J.Y. Synthesis and characterization of $\mathrm{LiNi}_{1-\mathrm{x}-\mathrm{y}} \mathrm{Co}_{\mathrm{x}} \mathrm{Mn}_{\mathrm{y}} \mathrm{O}_{2}$ as the cathode materials of secondary lithium batteries. J. Power Sour. 1999, 81, 416-419. [CrossRef]

7. Hwang, B.J.; Tsai, Y.W.; Carlier, D.; Ceder, G. A combined computational/experimental study on $\mathrm{LiNi}_{1 / 3} \mathrm{Co}_{1 / 3} \mathrm{Mn}_{1 / 3} \mathrm{O}_{2}$. Chem. Mater. 2003, 15, 3676-3682. [CrossRef]

8. Lu, Z.H.; MacNeil, D.D.; Dahn, J.R. Layered $\mathrm{Li}\left[\mathrm{Ni}_{\mathrm{x}} \mathrm{Co}_{1-2 \mathrm{x}} \mathrm{Mn}_{\mathrm{x}}\right] \mathrm{O}_{2}$ cathode materials for lithium-ion batteries. Electrochem. Solid State Lett. 2001, 4, A200-A203. [CrossRef]

9. MacNeil, D.D.; Lu, Z.; Dahn, J.R. Structure and electrochemistry of $\mathrm{Li}\left[\mathrm{Ni}_{\mathrm{x}} \mathrm{Co}_{1-2 \mathrm{x}} \mathrm{Mn}_{\mathrm{x}}\right] \mathrm{O}_{2}(0 \leq \mathrm{x} \leq 1 / 2)$. J. Electrochem. Soc. 2002, 149, A1332-A1336. [CrossRef]

10. Jouanneau, S.; Dahn, J.R. Preparation, structure, and thermal stability of new $\operatorname{NixCo}_{1-2 x} \mathrm{Mn}_{\mathrm{x}}(\mathrm{OH})_{2}(0 \leq \mathrm{x} \leq 1 / 2)$ phases. Chem. Mater. 2003, 15, 495-499. [CrossRef]

11. Jouanneau, S.; Eberman, K.W.; Krause, L.J.; Dahn, J.R. Synthesis, Characterization, and Electrochemical Behavior of Improved $\mathrm{Li}_{[}\left[\mathrm{Ni}_{\mathrm{x}} \mathrm{Co}_{1-2 \mathrm{x}} \mathrm{Mn}_{\mathrm{x}}\right] \mathrm{O}_{2}(0.1 \leq \mathrm{x} \leq 0.5)$. J. Electrochem. Soc. 2003, 150, A1637. [CrossRef]

12. Lee, B.R.; Noh, H.J.; Myung, S.T.; Amine, K.; Sun, Y.K. High-Voltage Performance of Li Ni $\mathrm{Ni}_{0.55} \mathrm{Co}_{0.15} \mathrm{Mn}_{0.30}$ $\mathrm{O}_{2}$ Positive Electrode Material for Rechargeable Li-Ion Batteries. J. Electrochem. Soc. 2011, 158, A180-A186. [CrossRef]

13. Nam, K.-M.; Kim, H.-J.; Kang, D.-H.; Kim, Y.-S.; Song, S.-W. Ammonia-free coprecipitation synthesis of a Ni-Co-Mn hydroxide precursor for high-performance battery cathode materials. Green Chem. 2015, 17, 1127-1135. [CrossRef] 
14. Cho, T.H.; Park, S.M.; Yoshio, M.; Hirai, T.; Hideshima, Y. Effect of synthesis condition on the structural and electrochemical properties of $\mathrm{Li}\left[\mathrm{Ni}_{1 / 3} \mathrm{Mn}_{1 / 3} \mathrm{Co}_{1 / 3}\right] \mathrm{O}_{2}$ prepared by carbonate co-precipitation method. J. Power Sour. 2005, 142, 306-312. [CrossRef]

15. Park, S.H.; Kang, S.H.; Belharouak, I.; Sun, Y.K.; Amine, K. Physical and electrochemical properties of spherical $\mathrm{Li}_{1+x}\left(\mathrm{Ni}_{1 / 3} \mathrm{Co}_{1 / 3} \mathrm{Mn}_{1 / 3}\right)_{(1-x)} \mathrm{O}_{2}$ cathode materials. J. Power Sour. 2008, 177, 177-183. [CrossRef]

16. Wu, K.C.; Wang, F.; Gao, L.L.; Li, M.R.; Xiao, L.L.; Zhao, L.T.; Hu, S.J.; Wang, X.J.; Xu, Z.L.; Wu, Q.G. Effect of precursor and synthesis temperature on the structural and electrochemical properties of $\mathrm{Li}\left(\mathrm{Ni}_{0.5} \mathrm{Co}_{0.2} \mathrm{Mn}_{0.3}\right) \mathrm{O}_{2}$. Electrochim. Acta 2012, 75, 393-398. [CrossRef]

17. Wang, D.; Belharouak, I.; Koenig, G.M.; Zhou, G.; Amine, K. Growth mechanism of $\mathrm{Ni}_{0.3} \mathrm{Mn}_{0.7} \mathrm{CO}_{3}$ precursor for high capacity Li-ion battery cathodes. J. Mater. Chem. 2011, 21, 9290. [CrossRef]

18. Li, D.C.; Noguchi, H.; Yoshio, M. Electrochemical characteristics of $\mathrm{LiNi}_{0.5-\mathrm{x}} \mathrm{Mn}_{0.5-\mathrm{x}} \mathrm{Co}_{2 \mathrm{x}} \mathrm{O}_{2}(0<\mathrm{x} \leq 0.1)$ prepared by spray dry method. Electrochim. Acta 2004, 50, 427-430.

19. Kim, J.-M.; Chung, H.-T. Role of transition metals in layered $\mathrm{Li}[\mathrm{Ni}, \mathrm{Co}, \mathrm{Mn}] \mathrm{O}_{2}$ under electrochemical operation. Electrochim. Acta 2004, 49, 3573-3580. [CrossRef]

20. Na, S.H.; Kim, H.S.; Moon, S.I. The effect of Si doping on the electrochemical characteristics of $\mathrm{LiNi}_{\mathrm{x}} \mathrm{Mn}_{\mathrm{y}} \mathrm{Co}_{(1-\mathrm{x}-\mathrm{y})} \mathrm{O}_{2}$. Solid State Ion. 2005, 176, 313-317. [CrossRef]

21. Li, J.G.; He, X.M.; Zhao, R.S.; Wan, C.R.; Jiang, C.Y.; Xia, D.G.; Zhang, S.C. Stannum doping of layered $\mathrm{LiNi}_{3 / 8} \mathrm{Co}_{2 / 8} \mathrm{Mn}_{3 / 8} \mathrm{O}_{2}$ cathode materials with high rate capability for Li-ion batteries. J. Power Sour. 2006, 158, 524-528. [CrossRef]

22. Sun, Y.K.; Myung, S.T.; Kim, M.H.; Prakash, J.; Amine, K. Synthesis and characterization of Li $\left(\mathrm{Ni}_{0.8} \mathrm{Co}_{0.1} \mathrm{Mn}_{0.1}\right)_{(0.8)}\left(\mathrm{Ni}_{0.5} \mathrm{Mn}_{0.5}\right)_{(0.2)} \mathrm{O}_{2}$ with the microscale core-shell structure as the positive electrode material for lithium batteries. J. Am. Chem. Soc. 2005, 127, 13411-13418. [CrossRef] [PubMed]

23. Sun, Y.K.; Chen, Z.; Noh, H.J.; Lee, D.J.; Jung, H.G.; Ren, Y.; Wang, S.; Yoon, C.S.; Myung, S.T.; Amine, K. Nanostructured high-energy cathode materials for advanced lithium batteries. Nat. Mater. 2012, 11, $942-947$. [CrossRef] [PubMed]

24. Kiziltas-Yavuz, N.; Herklotz, M.; Hashem, A.M.; Abuzeid, H.M.; Schwarz, B.; Ehrenberg, H.; Mauger, A.; Julien, C.M. Synthesis, structural, magnetic and electrochemical properties of $\mathrm{LiNi}_{1 / 3} \mathrm{Mn}_{1 / 3} \mathrm{Co}_{1 / 3} \mathrm{O}_{2}$ prepared by a sol-gel method using table sugar as chelating agent. Electrochim. Acta 2013, 113, 313-321. [CrossRef]

25. Chen, C.H.; Wang, C.J.; Hwang, B.J. Electrochemical performance of layered $\mathrm{Li} \mathrm{Ni}_{\mathrm{x}} \mathrm{Co}_{1-2 \mathrm{x}} \mathrm{Mn}_{\mathrm{x}} \mathrm{O}_{2}$ cathode materials synthesized by a sol-gel method. J. Power Sour. 2005, 146, 626-629. [CrossRef]

26. Gan, C.L.; Hu, X.H.; Zhan, H.; Zhou, Y.H. Synthesis and characterization of $\mathrm{Li}_{1.2} \mathrm{Ni}_{0.6} \mathrm{Co}_{0.2} \mathrm{Mn}_{0.2} \mathrm{O}_{2+\delta}$ as a cathode material for secondary lithium batteries. Solid State Ion. 2005, 176, 687-692. [CrossRef]

27. Zhang, S.; Qiu, X.; He, Z.; Weng, D.; Zhu, W. Nanoparticled $\mathrm{Li}\left(\mathrm{Ni}_{1 / 3} \mathrm{Co}_{1 / 3} \mathrm{Mn}_{1 / 3}\right) \mathrm{O}_{2}$ as cathode material for high-rate lithium-ion batteries. J. Power Sour. 2006, 153, 350-353. [CrossRef]

28. Li, Y.; Han, Q.; Ming, X.; Ren, M.; Li, L.; Ye, W.; Zhang, X.; Xu, H.; Li, L. Synthesis and characterization of $\mathrm{LiNi}_{0.5} \mathrm{Co}_{0.2} \mathrm{Mn}_{0.3} \mathrm{O}_{2}$ cathode material prepared by a novel hydrothermal process. Ceram. Int. 2014, 40, 14933-14938. [CrossRef]

29. Qian, Y.X.; Deng, Y.F.; Shi, Z.C.; Zhou, Y.B.; Zhuang, Q.C.; Chen, G.H. Sub-micrometer-sized $\operatorname{LiMn}_{1.5} \mathrm{Ni}_{0.5} \mathrm{O}_{4}$ spheres as high rate cathode materials for long-life lithium ion batteries. Electrochem. Commun. 2013, 27, 92-95. [CrossRef]

30. Li, J.L.; Cao, C.B.; Xu, X.Y.; Zhu, Y.Q.; Yao, R.M. LiNi ${ }_{1 / 3} \mathrm{Co}_{1 / 3} \mathrm{Mn}_{1 / 3} \mathrm{O}_{2}$ hollow nano-micro hierarchical microspheres with enhanced performances as cathodes for lithium-ion batteries. J. Mater. Chem. A 2013, 1, 11848-11852. [CrossRef]

31. He, P.; Wang, H.; Qi, L.; Osaka, T. Electrochemical characteristics of layered $\mathrm{LiNi}_{1 / 3} \mathrm{Co}_{1 / 3} \mathrm{Mn}_{1 / 3} \mathrm{O}_{2}$ and with different synthesis conditions. J. Power Sour. 2006, 160, 627-632. [CrossRef]

32. Ju, J.H.; Ryu, K.S. Synthesis and electrochemical performance of $\mathrm{Li}\left(\mathrm{Ni}_{0.8} \mathrm{Co}_{0.15} \mathrm{Al}_{0.05}\right)_{0.8}\left(\mathrm{Ni}_{0.5} \mathrm{Mn}_{0.5}\right)_{0.2} \mathrm{O}_{2}$ with core-shell structure as cathode material for Li-ion batteries. J. Alloy. Compd. 2011, 509, 7985-7992. [CrossRef]

33. Xiang, Y.; Yin, Z.; Li, X. Synthesis and characterization of manganese-, nickel-, and cobalt-containing carbonate precursors for high capacity Li-ion battery cathodes. J. Solid State Electrochem. 2014, 18, 2123-2129. [CrossRef] 
34. Luo, X.; Wang, X.; Liao, L.; Gamboa, S.; Sebastian, P.J. Synthesis and characterization of high tap-density layered $\mathrm{Li} \mathrm{Ni}_{(1 / 3)} \mathrm{Co}_{(1 / 3)} \mathrm{Mn}_{(1 / 3)} \mathrm{O}_{(2)}$ cathode material via hydroxide co-precipitation. J. Power Sour. 2006, 158, 654-658. [CrossRef]

35. Atsumi, T.; Nakata, Y.; Kobayakawa, K.; Negishi, K.; Yamazaki, N.; Sato, Y. Particle size effect of LiCoO 2 powders on discharge performance of lithium ion batteries. Electrochemistry 2001, 69, 603-607.

36. Cho, M.Y.; Kim, H.; Kim, H.; Lim, Y.S.; Kim, K.B.; Lee, J.W.; Kang, K.; Roh, K.C. Size-selective synthesis of mesoporous $\mathrm{LiFePO}_{4} / \mathrm{C}$ microspheres based on nucleation and growth rate control of primary particles. J. Mater. Chem. A 2014, 2, 5922-5927. [CrossRef]

37. Van Bommel, A.; Dahn, J.R. Analysis of the Growth Mechanism of Coprecipitated Spherical and Dense Nickel, Manganese, and Cobalt-Containing Hydroxides in the Presence of Aqueous Ammonia. Chem. Mater. 2009, 21, 1500-1503. [CrossRef]

38. Myung, S.T.; Lee, M.H.; Komaba, S.; Kumagai, N.; Sun, Y.K. Hydrothermal synthesis of layered Li $\mathrm{Ni}_{1 / 3} \mathrm{Co}_{1 / 3} \mathrm{Mn}_{1 / 3} \mathrm{O}_{2}$ as positive electrode material for lithium secondary battery. Electrochim. Acta 2005, 50, 4800-4806. [CrossRef]

39. Wu, F.; Wang, M.; Su, Y.F.; Bao, L.Y.; Chen, S. A novel method for synthesis of layered $\mathrm{LiNi}_{1 / 3} \mathrm{Mn}_{1 / 3} \mathrm{Co}_{1 / 3} \mathrm{O}_{2}$ as cathode material for lithium-ion battery. J. Power Sour. 2010, 195, 2362-2367. [CrossRef]

40. Kim, H.; Min, K.I.; Inoue, K.; Im, D.J.; Kim, D.P.; Yoshida, J. Submillisecond organic synthesis: Outpacing Fries rearrangement through microfluidic rapid mixing. Science 2016, 352, 691-694. [CrossRef] [PubMed]

41. Whitesides, G.M. The origins and the future of microfluidics. Nature 2006, 442, 368-373. [CrossRef] [PubMed]

42. Elvira, K.S.; Solvas, X.C.I.; Wootton, R.C.R.; deMello, A.J. The past, present and potential for microfluidic reactor technology in chemical synthesis. Nat. Chem. 2013, 5, 905-915. [CrossRef] [PubMed]

43. Yoshida, J.I.; Nagaki, A.; Yamada, T. Flash chemistry: Fast chemical synthesis by using microreactors. Chem. Eur. J. 2008, 14, 7450-7459. [CrossRef] [PubMed]

44. Cho, J. $\mathrm{LiNi}_{0.74} \mathrm{Co}_{0.26-\mathrm{x}} \mathrm{Mg}_{\mathrm{x}} \mathrm{O}_{2}$ cathode material for a Li-ion cell. Chem. Mater. 2000, 12, 3089-3094. [CrossRef]

45. Leubner, I.H. Particle nucleation and growth models. Curr. Opin. Colloid Interface Sci. 2000, 5, 151-159. [CrossRef]

46. Li, J.F.; Xiong, S.L.; Li, X.W.; Qian, Y.T. Spinel $\mathrm{Mn}_{1.5} \mathrm{Co}_{1.5} \mathrm{O}_{4}$ core-shell microspheres as Li-ion battery anode materials with a long cycle life and high capacity. J. Mater. Chem. 2012, 22, 23254-23259. [CrossRef]

47. Jo, M.; Lee, Y.K.; Kim, K.M.; Cho, J. Nanoparticle-Nanorod Core-Shell $\mathrm{LiNi}_{0.5} \mathrm{Mn}_{1.5} \mathrm{O}_{4}$ Spinel Cathodes with High Energy Density for Li-Ion Batteries. J. Electrochem. Soc. 2010, 157, A841-A845. [CrossRef] 